ISSN: 2146-3042

DOI: $10.25095 /$ mufad.673733

\title{
BIST Şehir Endekslerine Ait Volatilitenin Modellenmesi*
}

\author{
Öyküm Esra Aşkın*
}

\section{$\ddot{O Z E T}$}

Borsa Istanbul (BIST) tarafindan hesaplanan şehir indeksleri bölgesel kalkınmanın önemli bir göstergesidir. Hesaplandı̆̆ bölgenin finansal durumuna ışık tutan şehir endeksleri, belirsizlik altında yatırım kararı veren yatırımcılar için oldukça yararlı bir rehber olma özelliği taşımaktadır. Bu sebeple son yıllarda bu şehirlere ait finansal performansın bir haritasını çizmek, hem yatırımcıların hem de araştırmacıların oldukça dikkatini çekmektedir. Bu öneminden hareketle, çalışmada Şubat 2009-Mart 2019 tarihleri arasında hesaplanan 9 şehir endeksi günlük getiri serilerine ait volatilite, farklı simetrik ve asimetrik koşullu değişen varyans modelleri ile tahmin edilmiştir. Finansal zaman serilerinin kalın kuyruklu yapısı dikkate alınmış ve hata terimlerinin koşullu dă̆llımını betimlemede sadece normal dă̆llım değil aynı zamanda Student-t ve Generalized Error Distribution (GED) kullanılmıştır. Uygun modelin seçiminde çeşitli model seçim kriterlerinin yanısıra getiri serileri ĕgitim ve test olarak ikiye ayrılmış, modellere ait öngörü performans ölçütleri hesaplanmıştır. Dikkat çeken en önemli sonuçlardan birisi Antalya şehir endeksi haricindeki tüm endeks getiri serilerinde asimetrik modellerin başarılı sonuçlar ürettiği görülmüşürr. Ayrıca Tekirdăg şehir endeksi dışındaki tüm endekslerde negatif şokların aynı büyüklükteki pozitif şoklara kıyasla daha fazla volatiliteye sebep olduğu bulunmuştur.

Anahtar Kelimeler: Volatilite, Şehir Endeksi, ARCH, GARCH

JEL Sınıflandırması: G1, C13, C51

\section{Modelling The Volatility Of ISE City Indexes}

\section{ABSTRACT}

City indexes calculated by Istanbul Stock Exchange (ISE) are important indicator of regional development. A city index, which shed light on the financial situation of the region, is a very useful guide for investors who decide an investment under uncertainty. For this reason, drawing a map of the financial performance of these cities attracts both investors and researchers in recent years. In this study, the volatility of 9 city index daily return series calculated between February 2009 and March 2019 was estimated with different symmetric and asymmetric conditional variance models. The heavy-tailed structure of financial time series was taken into account and not only the normal distribution but also Student-t and Generalized Error Distribution (GED) distribution were used to describe the conditional distribution of error terms. In addition to the various model selection criteria in the determination of the appropriate model, return series were split into two sets as training and test, and the forecasting performance criteria of the models were calculated. One of the most notable results is that asymmetric models produced successful results in all index return series except Antalya city index. In addition, negative shocks were found to cause more volatility than positive shocks of the same size in all indexes except the Tekirdağ.

Keywords: Volatility, City Indexes, ARCH, GARCH

Jel Classification: $61, C 13$, C51

* Makale Gönderim Tarihi: 25.03.2019, Makale Kabul Tarihi: 02.08.2019, Makale Türü: Araştırma Makalesi

* Dr.Öğr. Üyesi, Yıldız Teknik Üniversitesi, Fen-Edebiyat Fakültesi, oeyigit@ yildiz.edu.tr, Orcid ID: 00000001-7805-3979 


\section{GíRiş}

Borsa İstanbul (BIST), 4 Şubat 2009 tarihli 299 nolu genelgesi ile ana üretim ve ya da faaliyet merkezi aynı şehirde olan şirketlerin fiyat ve getiri performansının izlenmesi amacıyla şehir endekslerinin hesaplanmaya başlamasına karar verdiğini duyurmuştur. Buna göre Adana, Ankara, Antalya, Bursa, İstanbul, İzmir, Kayseri, Kocaeli ve Tekirdağ şehir endeksleri 16.02.2009 tarihinden itibaren hesaplanmaya başlanmıştır. 13.05.2011 tarihinden itibaren Balıkesir, 06.07.2012 tarihinden itibaren Denizli ve 05.12.2012 tarihinden itibaren Konya illerinde payları BIST'de payları işlem gören şirket sayısı gerekli sayıya ulaşmasıyla, hesaplanan şehir endeksi sayısı 12'ye ulaşmıştır.

Şehir endeksleri, BIST pazarlarında işlem gören ve ana üretim/hizmet faaliyetlerinin gerçekleştiği ya da şirket merkezinin bulunduğu şehre göre gruplandırılmış paylardan oluşmaktadır. Bir şehrin, şehir endeksinin hesaplanmaya başlanması için borsada payları işlem gören ve aşağ 1 daki kapsam çerçevesinde bulunan en az 5 şirketin ilgi şehirde bulunması yeterlidir (http://borsaistanbul.com/endeksler/bist-pay-endeksleri/sehir-endeksleri,2019);

- Üretim faaliyetinde bulunan şirketler, üretimlerinin en az \%50'sini ilgili şehirde gerçekleştiriyorsa bahsedilen şirketler ilgili şehir endeksi kapsamında yer alır.

- Hizmet şirketleri, faaliyet gelirlerinin en az \%50'sini ilgili şehirde elde ediyorsa bahsedilen şirketler ilgili şehir endeksi kapsamında yer alır.

- Üretimin faaliyetinde bulunan şirketler için üretimlerinin en az \%50'sinin bulunduğu veya hizmet şirketleri için faaliyet gelirlerinin en az \%50'sinin elde edildiği bir şehir bulunmuyorsa, şirket merkezinin bulunduğu şehir dikkate alınır ve bahsedilen şirketler ilgili şehir endeksi kapsamında yer alır.

Bayramoğlu ve Pekkaya (2010) çalışmalarında şehir endekslerinin bir performans göstergesi taşıdığını ve yatırımcıların ilgili şehirlerde yatırım kararı verme aşamasında oldukça etkin şekilde yararlanabileceği endeksler olduğuna değinmişlerdir. Ayrıca bu endekslerin mikro ölçekli analizler için veri niteliği taşıdığı ve performanslarının karşılaştırılarak yerel potansiyelin ortaya çıkmasında yararlanılacak önemli bir kaynak olduğunu belirtmişlerdir (Bayramoğlu ve Pekkaya, 2010:201).

Şehir endekslerinin ilgili kriterleri sağlayan en az 5 şirketin paylarından oluşan bir portföy olması, bu endekslerin finansal performanslarının nasıl olduğu ve şehirlerin bu açıdan farklılık gösterip göstermediği sorusunu doğurmaktadır. Şirket lokasyonlarının, ülkenin sosyo-ekonomik durumundan ve diğer borsayı etkileyen unsurlardan nasıl ve ne şekilde etkilendiğinin bilinmesi büyük önem arz etmektedir. Yatırımcıların gelecekte verecekleri kararlarda her türlü bilgiyi kullanacakları düşünüldüğünde, BIST şehir endeksleri, incelenen şehirde yatırım kararı vermede yol gösterici ekstra bir bilgi olma özelliğini taşımaktadır. $\mathrm{Bu}$ sebeple şehir endekslerinin karakteristik yapısını inceleme ve yatırımcılara o şehre ait finansal performansın bir haritasını çizme ihtiyacı doğmaktadır.

$\mathrm{Bu}$ çalışmada, BIST şehir endekslerine ait günlük getiri serileri incelenerek tanımlayıcı istatistikler ve tanısal testler yardımıyla serilerin genel özellikleri belirlenmiş ve aralarındaki benzerlikler/farklılıklar tanımlanmıştır. Günlük getiri serilerine ait volatilite, simetrik koşullu değişen varyans modellerinden autoregressive conditional heteroscedasticity $(\mathrm{ARCH})$, generalized ARCH (GARCH) ve GARCH-in-mean (GARCH-M); asimetrik koşullu 
değişen varyans modellerinden exponential GARCH (EGARCH), threshold GARCH (TGARCH) ve asymmetric power GARCH (APGARCH) ile tahmin edilmiştir. Model seçimlerinde, hata terimlerinin koşullu varyans dağılım yapısı dikkate alınarak sadece normal dağılım değil ayrıca Student-t ve GED dağılım alternatifleri kullanılmıştır. Böylelikle leptokurtik (normal dağılıma kıyasla kalın kuyruklu) dağılım özelliğine sahip şehir endeksi serilerdeki volatilitenin modellenmesinde, normal dağılım dışında diğer dağılım alternatiflerini de kullanılarak daha başarılı sonuçlar elde edilmesine imkan verilmiştir. Böylelikle her bir şehir endeksi için 18 farklı simetrik ve asimetrik koşullu değişen varyans modelleri tahmin edilmiş ve volatilitenin modellenmesinde çalışılan dönemler için en iyi performansı gösteren nihai model spesifikasyonu belirlenmişsir.

Nihai model spesifikasyonunu belirlemede sadece log likelihood (LL), Akaike information criterion (AIC), Schwarz information criterion (SIC) ve Hannan-Quinn information criterion (H-Q) gibi model seçim kriterlerinden yararlanılmamış, ayrıca modellerin öngörü performansları da farklı ölçütler hesaplanarak kıyaslanmıştır. Bunun için veri seti eğitim ve test olmak üzere ikiye ayrılmış ve öngörülere ait root mean square error (RMSE), mean absolute error (MAE), mean absolute percentage error (MAPE) ve bias proportion (sapma oranı) istatistikleri hesaplanmıştır. Böylelikle nihai model spesifikasyonunu belirlemede modellerin sadece tahmin güçleri değil, aynı zamanda öngörü güçleri de kıyaslanmıştır.

\section{LITERATÜR ÖZETİ}

Çalışmanın bu kısmı iki başlık halinde ayrı olarak ele alınmıştır. İlk olarak otoregresif koşullu değişen varyans tipi modellere yer verilmiş, sonrasında ise şehir endeksleri ile ilgili yapılan çalışmalar sunulmuştur.

\subsection{ARCH Tipi Modeller}

Floros (2008) çalışmasında, finansal zaman serilerinin çoğunda ortak olarak bulunan leptokurtiklik, volatilite kümelenmesi, uzun hafiza ve kaldıraç etkisi gibi önemli özelliklerin açıklanmasında doğrusal modellerin yetersiz kaldığını belirtmiştir. Seriler bu özelliklerden bir veya daha fazlasına sahipse, kurulan regresyon modelinde sabit varyans (homoskedasticity) varsayımı ihlal edilmektedir (Özden, 2008:340). ARCH, geleneksel zaman serisi modellerine bir alternatif olarak Engle (1982) tarafindan sunulmuş ve sabit varyans varsayımını bir kenara bırakmıştır. Burada, varyansın gecikmeli öngörü hatalarının karelerinin bir fonksiyonu olarak değişmesine izin verilmektedir (Gökçe, 2001:36). Daha sonra, koşullu varyansin sadece geçmiş hata karelerinin değil, aynı zamanda kendi geçmiş değerlerinin bir fonksiyonu olmasina imkân veren GARCH modeli Bollerslev (1986) tarafindan literatüre kazandırılmışıı. GARCH spesifikasyonu, koşullu varyansı ARMA sürecine benzer şekilde modellemektedir. Pagan ve Schwert (1990) çalışmalarında bu iki modeli karşılaştırarak, zaman serilerindeki koşullu varyansın (volatilitesinin) modellenmesinde GARCH tipi modelin daha tutarlı sonuçlar verdiğini göstermişlerdir. Engle vd. (1987) finansal serilerdeki getiri ve volatilite arasındaki ilişkiyi göz önüne almış ve ortalama eşitliğine koşullu varyansı ekleyerek GARCH-M modelini oluşturmuşlardır.

Nelson (1991) çalş̧masında, pozitif ve negatif şokların volatilitedeki asimetrik etkilerinin modellenmesine imkan veren EGARCH modelini ortaya koymuştur. $\mathrm{Bu}$ 
çalışmadan sonra birçok asimetrik koşullu değişen varyans modelleri literatürde yerini almıştır. TGARCH modeli Zakoian (1994) tarafından geliştirilmiş ve Fransız hisse senedi getiri volatilitesinin modellenmesinde kullanılmıştır. Glosten vd. (1993) tasarladıkları Glosten-Jagannathan-Runkle GARCH (GJR-GARCH) modelini New York Menkul Kıymetler Borsası verilerine uygulamışlardır. GJR-GARCH modeli, EGARCH modeline benzer şekilde volatilitedeki asimetrik etkileri ölçmekte ancak koşullu varyansın pozitif olma koşulunun sağlanması ve durağanlığının garanti edilmesi için modelin parametrelerini kısıtlamaktadır. Temel GARCH modeline kaldıraç etkisinin dâhil edildiği asimetrik üssel GARCH (APGARCH), volatilitedeki asimetrik etkiyi ele almanın yanı sira, uzun hafiza özelliğini de modellemekte başarılıdır (Dink vd., 1993:100). Sentana (1995) ise gecikmeli hata merkezlerinin sifirdan sabit değerlere kayan Quadratic GARCH (QGARCH) modelini geliştirmiştir. Bunlar dışında literatürde kaldıraç etkisini ele alan başka modeller de mevcuttur.

Zaman serilerinin varsayımlarından biri olan hataların normal dağılma özelliği bazı durumlarda geçerli olmayabilir. Özellikle serilerin kalın kuyruklu bir dağılım yapısı sergilemesi, araştırmacıları ekstrem üçüncü ve dördüncü momentlerin modellenmesinde daha iyi sonuçlar veren normal dağılım dışındaki diğer dağılım türlerini tercih etme yoluna iter. Hata terimi $\varepsilon_{t}$ koşullu dağılımının normal dağılım türüne göre modellenmesinin yanı sıra, literatürde birçok alternatif dağılım türü kullanılmaktadır. Bollerslev (1987), finansal zaman serilerinin kalın kuyruklu yapısından ötürü standardize hataların dağılımını yakalamada Student-t dağılımının normal dağılıma göre daha başarılı olduğunu göstermiş, GARCHStudent-t model spesifikasyonunu önermiştir. Benzer şekilde, Hsieh (1989), Baillie ve Bollerslev (1989), Bollerslev vd. (1992) ve Pagan (1996) Student-t dağılım tipini öneren yazarlardır. GED dağılım türünün GARCH modellerine uygulaması ilk olarak Nelson (1991) tarafından yapılmış, getiri volatilitesini modellemede diğer dağılım türlerine kıyasla daha başarılı olduğu sonucuna varmıştır. Benzer olarak Taylor (1994), Lopez (2001) ve Lee vd. (2001) GED dağılımının aşırı basık serileri modellemede daha başarılı sonuçlar verdiğini göstermişlerdir.

\section{2. Şehir Endeksleri}

BIST tarafından hesaplanan şehir endeksleri ile ilgili çalışmalar oldukça sınırlıdır. İlk olarak Bayramoğlu ve Pekkaya (2010) şehir endekslerini ele almış ve bu endekslerin temel istatistiksel yapılarını incelemişlerdir. Oynaklığı en yüksek endeksler Antalya, Kocaeli, Ankara ve Bursa olarak raporlanmış iken, oynaklığı en düşük olan endek Adana şehir endeksi olarak belirtilmiştir.

Aksoy (2013) çalışmasında finansal kriz döneminde yabancı yatırımcıların yatırım davranışlarını ele almış ve yabancı yatırımcıların firma tercihlerinde BIST şehir endeksleri içinde yer alan firmalar ile ilişkili olup olmadığını araştırmışlardır. Kurulan regresyon modeline firmaların şehir endeksi içinde yer alıp almadığı kukla değişkenler kullanılarak eklenmiştir. Analiz sonunda tahmin edilen regresyon katsayılarının pozitif olduğu görülmüş ve genel merkezleri bahsedilen şehirlerde yer alan firmalar için yabanıı payının daha yüksek olabileceği belirtilmiştir.

Aşkın ve Büyüklü (2014) çalışmalarında şehir endeksleri için gün anomalisi kavramını araştırmış, bu amaçla GARCH ve EGARCH model spesifikasyonları kullanarak haftanın 
günlerini kukla değişken olarak modellere eklemişlerdir. Çalışmada, Bursa ve Kayseri şehir endeksine uygun modelin EGARCH, Antalya ve Tekirdağ şehir endeksine uygun modelin GARCH olduğu belirtilmiştir. Buna ek olarak Antalya, Kayseri ve Tekirdağ şehir endeksleri volatilitelerinde sırasıyla pazartesi, salı ve salı/cuma anomalisi bulunurken; Bursa şehir endeksine ait getirilerde pazartesi etkisi bulunmuştur.

Çakır (2016) çalışmasında şehir endekslerinin performanslarını Sharpe, $\mathrm{M}^{2}$ ve Sortino gibi oranlar kullanarak ölçmüştür. Sonuçlar incelendiğinde Tekirdağ şehir endeksinin en yüksek, İstanbul şehir endeksinin ise en düşük performansa sahip olduğu bulunmuştur.

Atmaca'nın (2018) yapmış olduğu çalışma, BIST şehir endeksi, ham petrol, Türk Lirası ve Avro getiri serilerini içermektedir. Çalışmadaki temel amaç dinamik koşullu korelasyon GARCH modeliyle şehir endeksleri ve ham petrol arasındaki ikili oynaklıklar ve korelasyonları modellemektir. Antalya şehir endeksinin diğer endekslerin aksine petrol fiyatları ile anlamlı pozitif bir ilişkiye sahip olduğu gösterilmiştir. Şehir endekslerindeki oynaklıkların kalıcı olduğu ve uzun dönem denge noktasına en kısa yakınsama sağlayan şehir endeksinin Ankara olduğu belirtilmiştir. Ayrıca Kocaeli şehir endeksinin makroekonomik faktörlerden etkilenen en duyarlı endeks olduğu bulunmuştur.

Kula ve Baykut (2018) çalışmalarında şehir endekslerinin volatilite yapılarını ve rejim yapılarını incelemişlerdir. ARCH, GARCH, TGARCH, EGARCH ve PARCH modelleri arasından en uygun model Theil's inequality coefficient (TIC katsayısı) kullanarak yapılmıştır. Gün bazında volatilitesi en yüksek olan endeks Antalya şehir endeksi iken en düşük günlük volatiliteye sahip olan şehir endeksi Kocaeli'dir.

Yapraklı vd. (2018) çalışmasında şehir endekslerinin volatilite yapılarını ortaya koymak için GARCH, EGARCH ve TGARCH modelleri kullanmış ve her bir şehir endeksi için uygun olan model AIC bilgi kriteri yardımıyla seçilmiştir.

Bayrakdaroğlu ve Tepeli (2018) ise 12 şehir endeksine ait günlük getirileri kullanarak beta katsayısı hesaplanmıştır. Balıkesir, Kayseri, Antalya ve Adana şehir endeksi getirilerinin pazar portföyünden daha yüksek getiri sağladığı raporlanmıştır.

\section{VOLATILITENIN MODELLENMESI}

\subsection{Simetrik Koşullu Değişen Varyans Modelleri}

Engle (1982) tarafından geliştirilen ARCH(p) modeli aşağıdaki eşitlikler ile gösterilir;

$$
\begin{aligned}
& R_{t}=X_{t} v+\varepsilon_{t} \\
& \varepsilon_{t}=z_{t} \sigma_{t} \\
& \sigma_{t}^{2}=\alpha_{0}+\sum_{i=1}^{q} \alpha_{i} \varepsilon_{t-i}^{2}
\end{aligned}
$$


(1) numaralı eşitlik modelin koşullu ortalama, (2) numaralı eşitlik ise modelin koşullu varyans denklemidir. Burada koşullu varyans ya da bir başka değişle volatilitenin geçmiş hata terimlerinin doğrusal bir fonksiyonu olduğu açıkça görülmektedir. Koşullu varyansın negatif değer almaması için $\boldsymbol{\alpha}_{0}>\mathbf{0}$ ve $\boldsymbol{\alpha}_{\mathbf{i}} \geq \mathbf{0}$ parametre kısıtları mevcuttur. Diğer bir kısıt ise zayıf

kovaryans durağanlık şartıdır ve $\sum_{\mathrm{i}=1}^{\mathrm{q}} \boldsymbol{\alpha}_{\mathrm{i}}<\mathbf{1}$ koşulunun sağlanması gerekmektedir. Aksi halde süreç sonsuz bir varyansa sahip olacaktır (Engle, 1982:993).

ARCH modelindeki koşullu varyans eşitliğinde, hata terimlerinin geçmiş değerlerine ilave olarak, koşullu varyansın kendi geçmiş değerlerinin eklenmesiyle genişletilen GARCH(p,q) modeli Bollerslev (1986) tarafından tanımlanmıştır.

$$
\sigma_{\mathrm{t}}^{2}=\alpha_{0}+\sum_{\mathrm{i}=1}^{\mathrm{q}} \alpha_{\mathrm{i}} \varepsilon_{\mathrm{t}-\mathrm{i}}^{2}+\sum_{\mathrm{j}=1}^{\mathrm{p}} \beta_{\mathrm{j}} \sigma_{\mathrm{t}-\mathrm{j}}^{2}
$$

(1) numaralı eşitlik modelin koşullu ortalama, (3) numaralı eşitlik ise modelin koşullu varyans denklemidir. Koşullu varyansın negatif değer almaması için $\alpha_{0}>0, \alpha_{i} \geq 0$ ve $\beta_{\mathrm{j}} \geq 0$ parametre kısıtları mevcuttur. Diğer bir kısıt ise zayıf kovaryans durağanlık şartıdır ve $\sum_{i=1}^{q} \alpha_{i}+\sum_{j=1}^{p} \beta_{j}<1$ koşulunun sağlanması gerekmektedir. Bu değer 1'e yaklaştıkça yaşanan bir şokun direncinin artmakta olduğu söylenir. Eğer ARCH parametre toplamları GARCH parametre toplamların değerinden küçük kalırsa, piyasanın bir dönemden daha uzun hafizaya sahip olduğu, yani volatilitenin kendi geçmiş değerlerine karşı piyasada yer alan sürprizlerden daha duyarlı olduğu şeklinde yorumlanabilir (Çiçek ve Öztürk, 2007:101).

Finansal teoride yer alan bir varlığın beklenen getirisi ile risk derecesi arasındaki doğrusal ilişki göz önüne alınarak Engle vd. (1987) GARCH-M(p,q) modelini geliştirmişlerdir. (1) numaralı eşitlik ile gösterilen koşullu ortalamada denkleminde, açıklayıcı bir değişken olarak koşullu varyansı ekleyerek model aşağıdaki forma dönüşmüştür;

$$
\begin{aligned}
& \mathbf{R}_{\mathrm{t}}=\mathbf{X}_{\mathrm{t}} \mathbf{v}+\delta \sigma_{\mathrm{t}}^{2}+\varepsilon_{\mathrm{t}} \\
& \sigma_{\mathrm{t}}^{2}=\alpha_{0}+\sum_{\mathrm{i}=1}^{\mathrm{q}} \alpha_{\mathrm{i}} \varepsilon_{\mathrm{t}-\mathrm{i}}^{2}+\sum_{\mathrm{j}=1}^{\mathrm{p}} \beta_{\mathrm{j}} \sigma_{\mathrm{t}-\mathrm{j}}^{2}
\end{aligned}
$$

(4) numaralı koşullu ortalama denkleminde yer alan $\delta$, risk primi parametresidir. Eğer bu katsayı tahmin edilen modelde pozitif ve istatistiksel açıdan anlamlı ise bu demektir ki riskten kaçınan yatırımcı risk arttıkça yüksek getiri (yüksek risk primi) beklemektedir (Nyberg, 2010:3). GARCH-M modelinin (5) ile gösterilen koşullu varyans eşitliği, (3) ile gösterilen eşitlik için aynı kısıtları ve koşulları sağlamaktadır.

\subsection{Asimetrik Koşullu Değişen Varyans Modelleri}

GARCH modelleri, volatilite kümelenmesi ve leptokurtik dağılım yapısı gösteren serileri modellemede başarılı olsa da kaldıraç etkisini modellemede yetersizdir. Çünkü koşullu varyansı, geçmiş değerlerin aynı zamanda işaretinin değil sadece büyüklüğünün bir 
fonksiyonudur. Bu sebeple aynı büyüklükteki pozitif ve negatif şokların koşullu varyans üzerindeki asimetrik tepkisini incelemeye olanak tanıyan $\operatorname{EGARCH}(p, q)$ modeli Nelson (1991) tarafından geliştirilmiştir.

$$
\log \left(\sigma_{\mathrm{t}}^{2}\right)=\alpha_{0}+\sum_{\mathrm{i}=1}^{\mathrm{q}} \alpha_{\mathrm{i}}\left|\frac{\varepsilon_{\mathrm{t}-1}}{\sqrt{\sigma_{\mathrm{t}-1}^{2}}}-\mathrm{E}\left(\frac{\varepsilon_{\mathrm{t}-1}}{\sqrt{\sigma_{\mathrm{t}-1}^{2}}}\right)\right|+\gamma \frac{\varepsilon_{\mathrm{t}-1}}{\sqrt{\sigma_{\mathrm{t}-1}^{2}}}+\sum_{\mathrm{j}=1}^{\mathrm{p}} \beta_{\mathrm{j}} \log \left(\sigma_{\mathrm{t}-\mathrm{j}}^{2}\right)
$$

(6) nolu eşitliğin sol tarafı incelenecek olunursa koşullu varyansın logaritmik olarak modellendiği görülmektedir. $\mathrm{Bu}$ durum koşullu varyansın negatif olmamasını garanti etmektedir. Diğer bir deyişle, tahmin edilen GARCH parametrelerinin işareti negatif olsa dahi, logaritmik dönüşüm sayesinde koşullu varyans daima pozitif olacak, model üzerinde herhangi bir parametre işaret kısıtına gerek duyulmayacaktır. Kaldıraç etkisinin varlığı $\gamma$ asimetri parametresi ile test edilir. $\gamma>0$ ve seçilen önem seviyesinde istatistiksel olarak anlamlı ise kaldıraç etkisinin varlığından söz edilir ve negatif şokların koşullu varyansı yükseltme eğiliminde olduğu söylenebilir (Alizadeh ve Nomikos, 2009:91). Eğer $\gamma=0$ ise pozitif ve negatif şoklar volatilitede üzerinde simetrik etkiler bırakmaktadır. Volatilitenin kalıcılığı (persistence) ise $\beta$ parametreleri ile ölçülür. Toplamlarının göreceli olarak büyük olması, piyasadaki bir dalgalanmanın ardından oynaklığın ortadan kaybolmasının uzun süreceği anlamına gelmektedir (Alexander, 2008:154). Çiçek (2010:18) bu durumu "koşulsuz varyans sonludur ve volatiliteye gelen şoklar yüksek derecede kalıcı etkiler" şeklinde tanımlamıştır.

Şokların volatilite üzerindeki etkisinin asimetrik olduğu varsayımına dayanan bir diğer eşik değerli GARCH, diğer bir değişle TGARCH(p,q) modelidir. Orijinal TGARCH modeli, $\sigma_{\mathrm{t}}^{2}$ kullanılması yerine $\sigma$ kullanılarak ilk defa Zakoian (1994) tarafından önerilmiştir. TGARCH modeli aynı zamanda GJR modeli olarak da adlandırılır çünkü Glosten vd. (1993) temelde aynı yapıda olduğunu göstermişlerdir (Zivot, 2008:18). Model, aşağıdaki koşullu varyans eşitliğine sahiptir;

$$
\sigma_{\mathrm{t}}^{2}=\alpha_{0}+\sum_{\mathrm{i}=1}^{\mathrm{q}} \alpha_{\mathrm{i}} \varepsilon_{\mathrm{t}-\mathrm{i}}^{2}+\sum_{\mathrm{i}=1}^{\mathrm{q}} \gamma_{\mathrm{i}} \mathrm{S}_{\mathrm{t}-\mathrm{i}} \varepsilon_{\mathrm{t}-\mathrm{i}}^{2}+\sum_{\mathrm{j}=1}^{\mathrm{p}} \beta_{\mathrm{j}} \sigma_{\mathrm{t}-\mathrm{j}}^{2}
$$

Modelde $\mathrm{S}_{\mathrm{t}-\mathrm{i}} ; \varepsilon_{\mathrm{t}-\mathrm{i}}<0$ ise $1, \varepsilon_{\mathrm{t}-\mathrm{i}} \geq 0$ ise 0 değerini alır. $\varepsilon_{\mathrm{t}-\mathrm{i}}=0$ eşik değer olarak kabul edilir ve bu değerin üstünde veya altında olmasına bağlı olarak $\varepsilon_{\mathrm{t}-\mathrm{i}}^{2}$ 'nin koşullu varyans üzerindeki etkisi farklılaşır. Asimetri parametresi $\gamma_{i}>0$ ve istatistiksel olarak anlamlı ise, olumsuz şoklar volatiliteyi olumlu şoklara kıyasla daha güçlü etki ederek kaldıraç etkisinden söz edilebilinecektir (Miron ve Tudor, 2010:79). Bu modelde de parametrelerin negatif olmama kısıtı mevcuttur ve koşullu varyansın zayıf kovaryans durağanlık koşulu $\left(\left(\alpha_{\mathrm{i}}+\gamma_{\mathrm{i}}\right) / 2\right)+\beta_{\mathrm{j}}<1$ ile sağlanmaktadır.

Varyans yerine standart sapmanın kullanıldığı GARCH modelinde kaldıraç etkisini göz önüne alarak Dink vd. (1993) asimetrik üslü GARCH, modelini geliştirmişlerdir. APGARCH modelinin koşullu varyans eşitliği aşağıdaki gibidir;

$$
\sigma_{\mathrm{t}}^{\mathrm{d}}=\alpha_{0}+\sum_{\mathrm{i}=1}^{\mathrm{q}} \alpha_{\mathrm{i}}\left(\left|\varepsilon_{\mathrm{t}-\mathrm{i}}\right|+\gamma_{\mathrm{i}} \varepsilon_{\mathrm{t}-\mathrm{i}}\right)^{\mathrm{d}}+\sum_{\mathrm{j}=1}^{\mathrm{p}} \beta_{\mathrm{j}} \sigma_{\mathrm{t}-\mathrm{j}}^{\mathrm{d}}
$$


(8) numaralı eşitlikte d pozitif üstür. $\mathrm{d}=2$ ise model asimetrik GARCH' a indirgenir. $\mathrm{d}=1$ ise PGARCH modeli $\sigma_{\mathrm{t}}$ cinsinden belirtilir ve aykırı değerlere karşı $\mathrm{d}=2$ olması durumundan az hassas olma eğilimindedir. Ayrıca ilave olarak tahmin edilen üs parametresi modelin esnekliğini arttırmaktadır (Zivot, 2009:18). $\gamma_{i}$ kaldıraç etkisini gösteren bilinmeyen parametredir ve sıfır olması durumunda model standart GARCH modeline dönüşmektedir. APGARCH modelinde tahmin edilen parametrelere kisitlamalar getirerek simetrik ve asimetrik ARCH modellerine ulaşılabilir.

\subsection{Koşullu Olasılık Dağılım Türleri}

(1) numaralı denklemde gösterilen $\varepsilon_{t}=z_{t} \sigma_{t}$ eşitliğinde $\varepsilon_{t}$ hata terimini, $\sigma_{t}$ ise volatiliteyi göstermektedir. $z_{t}$, bağımsız özdeş dağılan bir rasgele değişkendir ve sıfır ortalamayla D dağılmaktadır $\left(\mathrm{z}_{\mathrm{t}} \sim \mathrm{D}\right)$. Dağılım türü D’nin normal, Student-t ve genelleştirilmiş hata dağılımı (GED) olduğu varsayılmış, çalışmada hataların koşullu dağılımına ilişkin bahsi geçen üç dağılım tipi kullanılmıştır. Tablo 1'de bu üç dağılımın olasılık yoğunluk fonksiyonları (f) ve log-olabilirlik fonksiyonları (L) verilmiştir. Log-olabilirlik fonksiyonlarının maksimize edilmesiyle bilinmeyen parametre vektörünün en çok olabilirlik tahminleri elde edilir.

Tablo 1. Normal, Student-t ve GED Olasılık Yoğunluk ve Log-olabilirlik Fonksiyonlar1

\begin{tabular}{|c|c|}
\hline Normal & $\begin{array}{l}\mathrm{f}\left(\varepsilon_{\mathrm{t}}\right)=1 / \sqrt{2 \pi \sigma^{2}} \mathrm{e}^{-\frac{1}{2}\left(\frac{\varepsilon_{\mathrm{t}}^{2}}{\sigma_{\mathrm{t}}^{2}}\right)} \\
\mathrm{L}_{\text {normal }}=-\frac{1}{2} \sum_{\mathrm{t}}\left[\ln (2 \pi)+\ln \left(\sigma_{\mathrm{t}}^{2}\right)+\mathrm{z}_{\mathrm{t}}\right] \\
\mathrm{z}_{\mathrm{t}}=\frac{\mathrm{s}_{\mathrm{t}}}{\sigma_{\mathrm{t}}}(\text { standardize artiklar })\end{array}$ \\
\hline Student-t & $\begin{array}{l}\mathrm{f}\left(\mathrm{z}_{\mathrm{t}} / \mathrm{V}\right)=\frac{1}{\sqrt{(\mathrm{v}-2) \mathrm{B}\left(\frac{1}{2}, \frac{\mathrm{v}}{2}\right)}} \frac{1}{\left[1+\frac{\mathrm{z}_{\mathrm{t}}^{2}}{(\mathrm{v} / 2)}\right]^{(\mathrm{v}+1) / 2}} \\
\mathrm{~L}_{\mathrm{student}}=\ln \left[\Gamma\left(\frac{(\mathrm{v}+1)}{2}\right)\right]-\ln \left[\Gamma\left(\frac{\mathrm{v}}{2}\right)\right]-\frac{1}{2} \ln [\pi(\mathrm{v}-2)]-\frac{1}{2} \sum_{\mathrm{t}=1}^{\mathrm{T}}\left[\ln \sigma_{\mathrm{t}}^{2}+(\mathrm{v}+1) \ln (\right. \\
\left.\left.\frac{\mathrm{z}_{\mathrm{t}}^{\mathrm{z}}}{(\mathrm{v} / 2)}\right)\right] \\
; \\
\mathrm{z}_{\mathrm{t}}=\frac{\mathrm{s}_{\mathrm{t}}}{\sigma_{\mathrm{t}}} \text { (standardize artıklar) ve } \mathrm{v}>0 \text { şekil parametresi }\end{array}$ \\
\hline GED & $\begin{array}{l}\mathrm{f}\left(\mathrm{z}_{\mathrm{t}} / \mathrm{v}\right)=\frac{\mathrm{v}}{\lambda_{\mathrm{v}} 2^{(\mathrm{v}+1 / \mathrm{v})} \Gamma(1 / \mathrm{v})} \exp \left(-\frac{1}{2}\left|\frac{\mathrm{z}_{\mathrm{t}}}{\lambda_{\mathrm{t}}}\right|^{\mathrm{v}}\right) ; \lambda_{\mathrm{t}}=\left[\frac{2^{(-\mathrm{z} / \mathrm{v}) \Gamma(1 / \mathrm{v})}}{\Gamma(3 / \mathrm{v})}\right]^{1 / 2} \\
\mathrm{~L}_{\mathrm{GED}}=\ln \left(\mathrm{v} / \lambda_{\mathrm{v}}\right)-\frac{1}{2}\left|\frac{\mathrm{z}_{\mathrm{t}}}{\lambda_{\mathrm{t}}}\right|^{\mathrm{v}}-\left(1+\frac{1}{\mathrm{v}}\right) \ln (2)-\ln \Gamma(1 / \mathrm{v})-\frac{1}{2} \ln \sigma_{\mathrm{t}}^{2} \\
\mathrm{z}_{\mathrm{t}}=\frac{\mathrm{s}_{\mathrm{t}}}{\sigma_{\mathrm{t}}} \text { (standardize artılar) ve } 0<\mathrm{v} \leq+\infty \text { şekil parametresi }\end{array}$ \\
\hline
\end{tabular}

Student-t dağılımı için $2<v=\infty$ koşulundaki şekil parametresi aynı zamanda leptokurtikliğin derecesini açıklamaya yaramaktadır. $v$ değeri azaldıkça leptokurtiklik 
belirginleşmeye başlar. $1 / \mathrm{v} \rightarrow \infty$ durumunda dağ 1 lım standart normale yakınsar. GED' de $\mathrm{v}$ dağılımın kuyruk yapısını belirleyen pozitif şekil parametresidir. $v=1$ ise Laplace, $v=2$ ise standart normal, $\mathrm{v} \rightarrow \infty$ durumunda ise dağılım tekdüze dağılımına indirgenir (Kovacic, 2007:13).

\section{TANIMLAYICI İSTATISTIKLER VE TANISAL TESTLER}

Çalışmada, BIST tarafindan hesaplanan Adana, Ankara, Antalya, Bursa, İstanbul, İzmir, Kayseri, Kocaeli ve Tekirdağ şehir endeksine ait 16.02.2009-08.03.2019 tarihlerini kapsayan günlük getiriler kullanılmıştır. $P_{t}, t$ günündeki 2. Seans kapanış fiyatını gösterdiğinde, günlük getiri değerleri $R_{t}=\log \left(P_{t} / P_{t-1}\right)$ formülü yardımıyla hesaplanmıştır. Balıkesir, Denizli ve Konya şehir endeksleri haricindeki diğer 9 şehir endeksi eş zamanlı hesaplanmaya başlanmışıı. Sözü edilen 3 şehir endeksinin hesaplanmaya başlandığı tarihler birbirlerinden farklılık araz etmekte, dolayısıyla veri bütünlüğünün sağlanması amacıyla bu 3 endeks analiz kapsamına alınmamıştır. Tüm veriler BIST elektronik veri dağıtım sisteminden ve http://tr.investing.com internet adresinden temin edilmiştir. Tablo 2, her bir şehir endeksi getiri serisine ilişkin tanımlayıcı istatistikleri göstermektedir.

Tablo 2. Şehir Endeksleri Getiri Serilerine Ait Tanımlayıcı İstatistikler

\begin{tabular}{|l|c|c|c|c|c|c|c|}
\hline & N & Ortalama & $\begin{array}{c}\text { En } \\
\text { Yüksek }\end{array}$ & $\begin{array}{c}\text { Standart } \\
\text { Sapma }\end{array}$ & Çarpıklık & Basıklık & $\begin{array}{c}\text { Jarque- } \\
\text { Bera }\end{array}$ \\
\hline XSADA & 2532 & 0.000337 & 0.044960 & 0.007356 & -0.472698 & 10.76420 & $6454.127^{* *}$ \\
\hline XSANK & 2532 & 0.000245 & 0.031330 & 0.006363 & -0.585962 & 7.263423 & $2062.544^{* *}$ \\
\hline XSANT & 2532 & 0.000116 & 0.047870 & 0.008978 & -0.479575 & 8.114794 & $2857.054^{* *}$ \\
\hline XSBUR & 2532 & 0.000280 & 0.048280 & 0.007423 & -0.589539 & 8.735358 & $3617.021^{* *}$ \\
\hline XSİST & 2532 & 0.000232 & 0.026330 & 0.005498 & -0.685131 & 7.423539 & $2262.480^{* *}$ \\
\hline XSİZM & 2532 & 0.000304 & 0.034900 & 0.006470 & -0.630540 & 6.694070 & $1607.449^{* *}$ \\
\hline XSKAY & 2532 & 0.000404 & 0.048270 & 0.007756 & -0.700557 & 8.010422 & $2855.615^{* *}$ \\
\hline XSKOC & 2532 & 0.000390 & 0.033120 & 0.007141 & -0.541156 & 6.432988 & $1366.943^{* *}$ \\
\hline XSTKR & 2532 & 0.000318 & 0.100660 & 0.010056 & 0.387198 & 20.82818 & $33595.82^{* *}$ \\
\hline
\end{tabular}

Not: "**": \%5 önem seviyesinde istatistiksel olarak anlamlı olduğunu göstermektedir.

Tanımlayıc1 istatistiklere göre en yüksek ilk iki getiri ortalamas1 Kayseri ve Kocaeli şehir endeksine aitken en düşük getiri ortalaması Antalya endeksine aittir. En düşük standart sapma sirasıyla İstanbul ve Ankara şehir endekslerine aitken Tekirdağ şehir endeksi en yüksek sapmaya sahiptir. Risk ölçüsü olarak standart sapma kullanılırsa Tekirdağ şehir endeksinin diğerlerine göre daha riskli olduğu görülmektedir. Tekirdağ dışındaki tüm endeks getiri serilerinin negatif çarpıklığa sahip olduğu görülmekte, dolayısıyla piyasalardaki negatif şokların pozitif şoklara kıyasla daha etkili olduğu yorumu yapılabilmektedir. Tekirdağ şehir endeksinin diğer serilerin tam tersi olmak üzere dağılışının sağa doğru uzun kuyruklu bir yapı gösterdiği söylenebilir. Basıklık katsayıları incelendiğinde ise tüm getiri serilerinin leptokurtik dağılım özelliği gösterdiği görülmektedir. Bununla birlikte normallikten sapmanın testinde kullanılan Jargue-Bera test istatistikleri, kritik ki-kare değerinden yüksek çıkmış, serilerin normal dağıldığını belirten yokluk hipotezi \%5 önem seviyesinde reddedilmiştir. 
Model çözümüne geçilmeden önce durağanlığının sınanması gerekmektedir. BIST şehir endekslerine ait getiri serilerinin durağan olup olmadığının araştırılmasında Genişletilmiş Dickey-Fuller (ADF) ve Philips-Perron (PP) birim kök testleri kullanılmıştır. PP testi parametrik bir test olmadığından normal dağılım göstermeyen serilerde daha sağlıklı sonuçlar elde edilmesine imkan vermektedir (Duran ve Şahin, 2006:62). Ayrıca serilerde otokorelasyon ve ARCH etkisi bulunması durumunda yüksek otokorelasyona ve heteroskedastisiteye (değişen varyans) karşı güvenilir bulunmaktadır (Çiçek, 2010:8).

Tablo 3. Şehir Endeksleri Getiri Serilerine Ait Tanımlayıcı İstatistikler

\begin{tabular}{|c|c|c|c|c|c|c|}
\cline { 2 - 6 } \multicolumn{2}{c|}{} & \multicolumn{3}{c|}{ ADF Test İstatistikleri } & \multicolumn{3}{c|}{ PP Test Ístatistikleri } \\
\cline { 2 - 7 } Endeksler & $\begin{array}{c}\text { Sabitsiz } \\
\text { trendsiz }\end{array}$ & $\begin{array}{c}\text { Sabitli } \\
\text { trendsiz }\end{array}$ & $\begin{array}{c}\text { Sabitli } \\
\text { trendli }\end{array}$ & $\begin{array}{c}\text { Sabitsiz } \\
\text { trendsiz }\end{array}$ & $\begin{array}{c}\text { Sabitli } \\
\text { trendsiz }\end{array}$ & $\begin{array}{c}\text { Sabitli } \\
\text { trendli }\end{array}$ \\
\hline XSADA & $-48.72^{* *}$ & $-48.81^{* *}$ & $-48.80^{* *}$ & $-48.73^{* *}$ & $-48.81^{* *}$ & $-48.81^{* *}$ \\
\hline XSANK & $-51.14^{* *}$ & $-51.21^{* *}$ & $-51.23^{* *}$ & $-51.17^{* *}$ & $-51.27^{* *}$ & $-51.32^{* *}$ \\
\hline XSANT & $-50.91^{* *}$ & $-50.91^{* *}$ & $-50.92^{* *}$ & $-50.91^{* *}$ & $-50.91^{* *}$ & $-50.92^{* *}$ \\
\hline XSBUR & $-51.19^{* *}$ & $-51.25^{* *}$ & $-51.29^{* *}$ & $-51.34^{* *}$ & $-51.45^{* *}$ & $-51.54^{* *}$ \\
\hline XSIST & $-49.63^{* *}$ & $-49.71^{* *}$ & $-49.74^{* *}$ & $-49.64^{* *}$ & $-49.73^{* *}$ & $-49.76^{* *}$ \\
\hline XSIZM & $-49.93^{* *}$ & $-50.03^{* *}$ & $-50.06^{* *}$ & $-49.93^{* *}$ & $-50.02^{* *}$ & $-50.06^{* *}$ \\
\hline XSKAY & $-45.85^{* *}$ & $-45.96^{* *}$ & $-45.95^{* *}$ & $-45.81^{* *}$ & $-45.96^{* *}$ & $-45.95^{* *}$ \\
\hline XSKOC & $-48.21^{* *}$ & $-48.34^{* *}$ & $-48.35^{* *}$ & $-48.22^{* *}$ & $-48.54^{* *}$ & $-48.58^{* *}$ \\
\hline XSTKR & $-49.84^{* *}$ & $-49.88^{* *}$ & $-49.96^{* *}$ & $-50.13^{* *}$ & $-50.11^{* *}$ & $-50.13^{* *}$ \\
\hline
\end{tabular}

Not: "**": \%5 önem seviyesinde istatistiksel olarak anlamlı olduğunu göstermektedir.

Tablo 3 incelenecek olunursa, her bir şehir endeksi için 3 farklı modele ait ADF ve PP test istatistikleri $\% 1, \% 5$ ve $\% 10$ önem seviyelerine ait MacKinnon kritik değerlerinden mutlak değerce büyüktür. Her bir getiri serisi için serinin birim köke sahip olduğunu belirten yokluk hipotezi, tüm önem seviyelerinde reddedilmiş ve serilerin durağan olduğu sonucuna ulaşılmıştır.

Serilerin durağanlığının sınanmasının ardından koşullu ortalama denklemini tahmin etmek için Box-Jenkins metodolojisine başvurulmuştur. $\operatorname{AR}(p), \operatorname{Ma}(q)$ ve $\operatorname{ARMA}(p, q)$ modelleri, en küçük kareler (EKK) yöntemi kullanılarak tahmin edilmiştir. Her bir endeksin koşullu ortalama denkleminin tahmininde en uygun $\mathrm{p}$-q değerleri ACF/PACF'ler yardımı ile belirlenmiş, uygun modelin seçilmesinde parametrelerin anlamlılığı aranmıştır. Ayrıca düşük AIC, SIC ve H-Q bilgi kriterlerleri dışında yüksek LL fonksiyon değeri model tercihinde aranan kriterlerdir. Uygun model belirlendikten sonra kullanılan spesifikasyonun hata terimlerinde ARCH etkilerinin bulunup bulunmadığ 1 Lagrange Çarpanları (LM) yardımıyla belirlenmiştir. ARCH-LM testinde "modelde ARCH etkisi yoktur" yokluk hipotezi farklı gecikmeler için seçilen anlamlılık düzeylerinde test edilmiştir. Tablo 4'de tüm şehir endeksleri için EKK yöntemi ile tahmin edilen ARMA(p,q) spesifikasyonu, belirlenen ARMA spesifikasyonuna ait log olabilirlik değerleri ve hata terimlerine ait ARCH-LM test istatistikleri verilmiştir (5 gecikme için). Tüm seriler için yapılan ARCH-LM testlerinde kurulan yokluk hipotezleri \%5 önem seviyesinde reddedilmiştir. Şehir endeksi getiri 
serilerinde değişen varyans sorunu vardır. Bu sebeple serilerdeki volatilite kümelenmesinin ve koşullu varyansın açıklanmasında otoregresif koşullu değişen varyans modellerinin kullanılması gerekmektedir.

Tablo 4. Şehir Endekslerine Uygun ARMA(p,q) Modellerine Ait Tanısal Testler

\begin{tabular}{|c|c|c|c|}
\hline Endeksler & ARMA(p,q) & LL & $\begin{array}{c}\text { ARCH-LM } \\
\text { F istatistiği }\end{array}$ \\
\hline XSADA & sabitli-ARMA(3,2) & 8850.841 & $25.8631^{* *}$ \\
\hline XSANK & ARMA(2,4) & 9221.279 & $30.4084^{* *}$ \\
\hline XSANT & ARMA(2,4) & 8349.805 & $28.4806^{* *}$ \\
\hline XSBUR & sabitli-ARMA(4,4) & 8836.750 & $19.0384^{* *}$ \\
\hline XSIST & sabitli-ARMA(4,4) & 9591.733 & $28.5077^{* *}$ \\
\hline XSIZM & sabitli-ARMA(3,3) & 9180.081 & $21.7755^{* *}$ \\
\hline XSKAY & sabitli-ARMA(2,3) & 8729.905 & $18.8586^{* *}$ \\
\hline XSKOC & sabitli-ARMA(2,2) & 8933.327 & $12.9253^{* *}$ \\
\hline XSTKR & ARMA(1,4) & 8067.984 & $116.6347^{* *}$ \\
\hline
\end{tabular}

Not: "**": \%5 önem seviyesinde istatistiksel olarak anlamlı olduğunu göstermektedir

Serilerde otoregresif koşullu değişen varyans modellerinin kullanılması gerekliliği belirlendikten sonra 9 şehir endeksi farklı modeller denenmiştir. Simetrik koşullu değişen varyans modellerinden $\operatorname{ARCH}(1), \operatorname{GARCH}(1,1)$ ve $\operatorname{GARCH}-\mathrm{M}(1,1)$; asimetrik koşullu değişen varyans modellerinden ise $\operatorname{EGARCH}(1,1), \quad \operatorname{TGARCH}(1,1)$ ve APGARCH $(1,1)$ modelleri, şehir endeksi getiri serileri için tahmin edilmiştir. Hata terimleri koşullu dağılımlarının, sadece normal dağılım tipi ile değil, aynı zamanda Student-t ve GED dağıldığı varsayımı altında her bir şehir endeksi için toplamda 18 farklı model tahmin edilmiş ve volatilitenin modellenmesinde en yüksek performansı gösteren model her bir endeks için ayrı ayrı belirlenmiştir. Modellerin performanslarının belirlenmesinde iki farklı yaklaşım eşanlı olarak kullanılmış ve adımsal olarak aşağıda verilmiştir.

Adım 1: İlk olarak yukarıda belirtilen 18 farklı simetrik ve asimetrik GARCH modeli 16.02.2009-08.03.2019 tarihleri için (tüm veri seti için) tahmin edilmiştir. Tahmin edilen modellerin varyans eşitliğindeki katsayıları istatistiksel olarak anlamlı değilse, bu modeller en iyi model arayışından çıkarılmıştır. Geriye kalan modellerin hata terimlerinde ARCH etkilerinin bulunup bulunmadığı ARCH-LM testiyle 1,5 ve 10 gecikme ile test edilmiştir. Değişen varyans sorunu ortadan kalkmayan modeller, en iyi model arayışından çıkarılmıştır. Böylece bu süreç sonunda en iyi olma potansiyeli taşıyan modellerin AIC, SIC ve LL ve H-Q model seçim ölçütleri hesaplanmış ve raporlanmıştır.

Adım 2: $\mathrm{Bu}$ adımda, Adım 1'de belirlenen ve en iyi olma potansiyeli taşıyan modellerin öngörü performansları ölçülmüş̧ür. Bunun için veri seti eğitim ve test olmak üzere iki alt gruba ayrılmıştır. Burada amaç, eğitim seti ile kurulan modelin öngörü performansını test seti ile ölçmektir. Eğitim seti verinin yaklaşık \%90'ını kapsayacak şekilde (16.02.200907.03.2018 tarihleri arası) şeçilmişken, test seti verinin kalan yaklaşık \%10'unu kapsamaktadır (08.03.2018-08.03.2019 tarihleri aras1). Öngörü performans ölçütü olarak RMSE, MAE, MAPE ve sapma oranı istatistikleri kullanılmıştır. RMSE, MAE ve MAPE ölçütleri gerçek değer ve öngörülen değer farkına (hatalara) dayanan hesaplamalar olup bu 
istatistiklerin düşük değerli olması model tercihinde aranan özelliktir. Sapma oranı ise, sistematik hatanın bir göstergesi olup, öngörülen serinin ortalamasının gerçek seri ortalamasından ne kadar uzakta olduğunu gösterir. Bu ölçüt sıfira ne kadar yakın olursa öngörü performansının o kadar iyi olduğu söylenir. Adım 1 ve Adım 2'de hesaplanan model seçim ve öngörü performans ölçütlerine dayanarak nihai en iyi model seçilmiştir.

\section{VERÍLERİN ANALİZI VE BULGULAR}

Adana şehir endeksi serisi için; volatilitenin modellenmesinde asimetri katsayılarının anlamlı olması ve ARCH etkisinin 1, 5 ve 10 gecikme için giderilmesi sebebiyle bu adımda en iyi olma potansiyeli taşıyan modellerin EGARCH ve APGARCH olduğu görülmüss ve bu modellere ait model seçim ölçütleri hesaplanarak Tablo 5'de verilmiştir. Ayrıca, 2. Adım'da bu iki modelin öngörü performanslarına yönelik ölçütler de aynı tabloda yer almıştır. Model seçim ve öngörü performans ölçütlerine göre en iyi modelin EGARCH olduğu ve bu endeks serisine ait tahminlerin hata terimlerinin koşullu dağ 1 lımlarını betimlemede en başarılı dağılım türünün normal dağılım olduğu görülmüştür.

Tablo 5. Adana Şehir Endeksi Getiri Serisine Ait Ölçütler

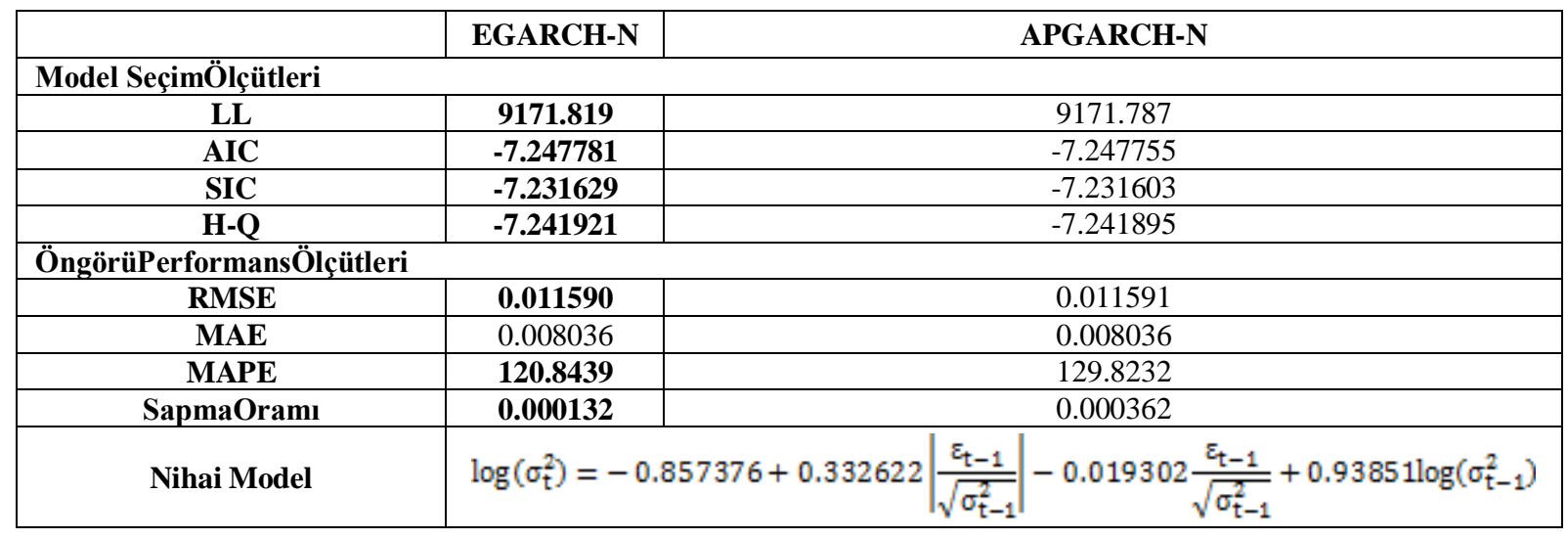

Ankara şehir endeksi serisi için en iyi olma potansiyeli taşıyan 6 farklı model belirlenmiş ve bu modellere ait model seçim ölçütleri ve öngörü performanslarına yönelik ölçütler Tablo 6'da verilmiştir. Model seçim ölçütlerinin tümüne ve RMSE ölçütüne göre en iyi model olan TGARCH, nihai model olarak seçilmiştir. Ayrıca tahminlerin hata terimlerinin koşullu dağılımlarını betimlemede en başarılı dağılım türünün Student-t olduğu görülmüştür.

Tablo 6. Ankara Şehir Endeksi Getiri Serisine Ait Ölçütler

\begin{tabular}{|c|c|c|c|c|c|c|}
\hline & $\begin{array}{c}\text { EGARCH } \\
\mathbf{N} \\
\end{array}$ & $\begin{array}{c}\text { EGARCH } \\
\text { GED }\end{array}$ & $\begin{array}{c}\text { TGARCH } \\
\mathbf{N} \\
\end{array}$ & $\begin{array}{c}\text { TGARCH } \\
\text { T } \\
\end{array}$ & $\begin{array}{c}\text { TGARCH } \\
\text { GED }\end{array}$ & $\begin{array}{c}\text { APGARCH } \\
\mathbf{N} \\
\end{array}$ \\
\hline \multicolumn{7}{|l|}{ Model SeçimÖlçütleri } \\
\hline $\mathbf{L L}$ & 9351.585 & 9423.217 & 9354.604 & 9436.929 & 9424.252 & 9348.133 \\
\hline AIC & -7.387814 & -7.44365 & -7.390201 & -7.45449 & -7.444468 & -7.385086 \\
\hline SIC & -7.373974 & -7.427503 & -7.376361 & -7.438343 & -7.428321 & -7.371245 \\
\hline H-Q & -7.382792 & -7.437792 & -7.385179 & -7.448631 & -7.43861 & -7.380064 \\
\hline \multicolumn{7}{|c|}{ ÖngörüPerformansÖlçütleri } \\
\hline RMSE & 0.007735 & 0.007727 & 0.007742 & 0.007726 & 0.007731 & 0.007731 \\
\hline MAE & 0.005902 & 0.005896 & 0.005906 & 0.005899 & 00.005899 & 0.005899 \\
\hline MAPE & 107.5143 & 105.1276 & 109.3882 & 106.0675 & 106.3765 & 106.3008 \\
\hline SapmaOranı & 0.003099 & 0.003054 & 0.003135 & 0.003068 & 0.003078 & 0.003077 \\
\hline Nihai Model & \multicolumn{6}{|c|}{$\sigma_{\mathrm{t}}^{2}=2.0 \mathrm{E}-0.6+0.057092 \varepsilon_{\mathrm{t}-1}^{2}+0.058307 \mathrm{~S}_{\mathrm{t}-1} \varepsilon_{\mathrm{t}-1}^{2}+0.856046 \sigma_{\mathrm{t}-1}^{2}$} \\
\hline
\end{tabular}


Antalya şehir endeksi serisinin asimetrik modellemelerde başarısız olması en dikkat çekici sonuçlardan biridir. Adım 1'de bu endeks serisine ait en iyi olma potansiyeli taşıyan modellerin GARCH tipi modeller olduğu görülmüss ve Adım 2'de bu modellere dayalı öngörü performansları hesaplanmıştır (Bkz. Tablo 7). Model seçim ölçütlerinin tümüne göre ve ayrica MAE ve MAPE öngörü performans ölçütlerine göre en iyi modelin GARCHStudent t olduğu sonucuna ulaşılmıştır.

Tablo 7. Antalya Şehir Endeksi Getiri Serisine Ait Ölçütler

\begin{tabular}{|c|c|c|c|}
\hline & GARCH-N & GARCH-T & GARCH-GED \\
\hline \multicolumn{4}{|l|}{ Model SeçimÖlçütleri } \\
\hline $\mathbf{L L}$ & 8489.856 & 8672.046 & 8652.997 \\
\hline AIC & -6.707396 & -6.850629 & -6.835571 \\
\hline SIC & -6.695863 & -6.836789 & -6.82173 \\
\hline H-Q & -6.703212 & -6.845608 & -6.830549 \\
\hline \multicolumn{4}{|c|}{ ÖngörüPerformansölçütleri } \\
\hline RMSE & 0.010266 & 0.010272 & 0.010274 \\
\hline MAE & 0.007250 & 0.007244 & 0.007249 \\
\hline MAPE & 116.6695 & 106.6415 & 109.2103 \\
\hline SapmaOranı & 0.000932 & 0.000994 & 0.000992 \\
\hline Nihai Model & \multicolumn{3}{|c|}{$\sigma_{\mathrm{t}}^{2}=7.47 \mathrm{E}-0.6+0.170312 \varepsilon_{\mathrm{t}-1}^{2}+0.758136 \sigma_{\mathrm{t}-1}^{2}$} \\
\hline
\end{tabular}

Adım 1'de Bursa şehir endeksi getiri serisinin tüm asimetrik koşullu değişen varyans modelleri için başarılı sonuçlar üretildiği görülmüştür. Bu sebeple Adım 2 için 9 adet asimetrik modelin öngörü performans ölçütleri hesaplanmıştır. Tablo 8 göz önüne alındığında, model seçim ölçütlerinin tümünde ve sapma oranı ölçütünde ortak olarak en iyi model APGARCH iken, RMSE, MAE ve MAPE ölçütleri için en düşük değer EGARCH modelinde yakalanmıştır. Model seçim ve tahmin performans ölçütlerinin tümü göz önüne alındığında en iyi modelin APGARCH ve ardından EGARCH olduğu görülmüş, nihai olarak APGARCH modeli seçilmiştir. Student-t dağılımı, nihai modele ait hata terimlerinin koşullu dağılımlarını betimlemede en başarılı dağılım türü olarak seçilmiştir.

Tablo 8. Bursa Şehir Endeksi Getiri Serisine Ait Ölçütler

\begin{tabular}{|c|c|c|c|c|c|c|}
\hline & $\begin{array}{c}\text { EGARCH } \\
\mathbf{N}\end{array}$ & $\begin{array}{c}\text { EGARCH } \\
T\end{array}$ & $\begin{array}{c}\text { EGARCH } \\
\text { GED }\end{array}$ & $\underset{\mathbf{N}}{\text { TGARCH }}$ & $\begin{array}{c}\text { TGARCH } \\
\mathbf{T}\end{array}$ & $\begin{array}{c}\text { TGARCH } \\
\text { GED }\end{array}$ \\
\hline \multicolumn{7}{|l|}{ Model SeçimÖlçüitleri } \\
\hline LL & 8953.789 & 9024.716 & 9015.02 & 8950.006 & 9022.071 & 9012.508 \\
\hline AIC & -7.078155 & -7.133477 & -7.125807 & -7.075163 & -7.131386 & -7.12382 \\
\hline SIC & -7.061998 & -7.115012 & -7.107341 & -7.059005 & -7.11292 & -7.105354 \\
\hline H-Q & -7.072293 & -7.126777 & -7.119107 & -7.0693 & -7.124685 & -7.11712 \\
\hline \multicolumn{7}{|c|}{ TahminPerformansölçütleri } \\
\hline RMSE & 0.007785 & 0.007812 & 0.007795 & 0.007796 & 0.007814 & 0.007809 \\
\hline MAE & 0.006004 & 0.006027 & 0.006012 & 0.006018 & 0.006028 & 0.006026 \\
\hline MAPE & 116.8672 & 126.7450 & 121.0419 & 119.7946 & 127.3820 & 125.0659 \\
\hline SapmaOranı & 0.014066 & 0.018595 & 0.016114 & 0.015135 & 0.019002 & 0.017634 \\
\hline \multicolumn{7}{|l|}{ Model SeçimÖlçütleri } \\
\hline & $\begin{array}{c}\text { APGARCH } \\
\mathbf{N}\end{array}$ & $\underset{T}{\text { APGARCH }}$ & $\begin{array}{c}\text { APGARCH } \\
\text { GED }\end{array}$ & & & \\
\hline $\mathbf{L L}$ & 8958.613 & 9028.104 & 9012.619 & & & \\
\hline AIC & -7.081972 & -7.136158 & -7.123907 & & & \\
\hline SIC & -7.065815 & -7.117692 & -7.105441 & & & \\
\hline H-Q & -7.07611 & -7.129458 & -7.117207 & & & \\
\hline \multicolumn{7}{|c|}{ TahminPerformansÖlçütleri } \\
\hline RMSE & 0.007794 & 0.007811 & 0.007806 & & & \\
\hline
\end{tabular}




\begin{tabular}{|c|c|c|c|c|c|c|}
\hline MAE & 0.006022 & 0.006027 & 0.006026 & & & \\
\hline MAPE & 118.7004 & 126.1958 & 123.9033 & & & \\
\hline SapmaOranı & $\mathbf{0 . 0 1 3 2 4 7}$ & 0.018255 & 0.016741 & & & \\
\hline Nihai Model & \multicolumn{6}{|c|}{$\sigma_{\mathrm{t}}^{\mathrm{d}}=0.000866+0.135868\left(\left|\varepsilon_{\mathrm{t}-1}\right|+0.439308 \varepsilon_{\mathrm{t}-1}\right)+0.776078 \sigma_{\mathrm{t}-1}^{1}$} \\
\hline
\end{tabular}

İstanbul şehir endeksi getiri serilerine ait sonuçlar Tablo 9'da verilmiştir. Model seçim ölçütlerinin tümünde ve MAPE dışında öngörü ölçütlerinin tümünde ortak olarak seriyi betimlemede en iyi modelin EGARCH olduğu görülmektedir. Student-t dağılımına yönelik en iyi ölçütler sayıca daha fazla olduğu için bu dağılım, nihai modele ait hata terimlerinin koşullu dağılımlarını betimlemede en başarılı dağılım türü olarak alınmıştır.

Tablo 9. İstanbul Şehir Endeksi Getiri Serisine Ait Ölçütler

\begin{tabular}{|c|c|c|c|c|c|c|c|c|}
\hline & $\begin{array}{c}\text { EGARCH } \\
\mathbf{N} \\
\end{array}$ & $\begin{array}{c}\text { EGARCH } \\
\text { T } \\
\end{array}$ & $\begin{array}{c}\text { EGARCH } \\
\text { GED }\end{array}$ & $\begin{array}{c}\text { TGARCH } \\
\mathbf{N} \\
\end{array}$ & $\begin{array}{c}\text { TGARCH } \\
\text { GED }\end{array}$ & $\begin{array}{c}\text { APGARCH } \\
\mathbf{N}\end{array}$ & $\begin{array}{c}\text { APGARCH } \\
\text { T } \\
\end{array}$ & $\begin{array}{l}\text { APGARCH } \\
\text { GED }\end{array}$ \\
\hline \multicolumn{9}{|c|}{ Model SeçimÖlçütleri } \\
\hline LL & 9722.867 & 9783.923 & 9775.45 & 9719.287 & 9765.948 & 9713.497 & 9783.083 & 9766.821 \\
\hline AIC & -7.686604 & -7.734117 & -7.727413 & -7.683771 & -7.719896 & -7.679191 & -7.733452 & -7.720586 \\
\hline SIC & -7.670446 & -7.715651 & -7.708947 & -7.667614 & -7.70143 & -7.663033 & -7.714986 & -7.70212 \\
\hline $\mathrm{H}-\mathrm{Q}$ & -7.680741 & -7.727416 & -7.720713 & -7.677909 & -7.713196 & -7.673328 & -7.726752 & -7.713886 \\
\hline \multicolumn{9}{|c|}{ ÖngörüPerformansölçütleri } \\
\hline RMSE & 0.005766 & 0.005786 & 0.005766 & 0.005768 & 0.005786 & 0.005775 & 0.005786 & 0.005785 \\
\hline MAE & 0.004458 & 0.004473 & 0.004456 & 0.004459 & 0.004473 & 0.004463 & 0.004473 & 0.004473 \\
\hline MAPE & 148.3015 & 140.4144 & 143.8836 & 150.4924 & 137.7619 & 137.1105 & 140.4230 & 137.4331 \\
\hline SapmaOranı & 0.002628 & 0.009435 & 0.003415 & 0.002924 & 0.009148 & 0.007023 & 0.009407 & 0.008961 \\
\hline $\begin{array}{l}\text { Nihai } \\
\text { Model }\end{array}$ & & & & & & & & \\
\hline
\end{tabular}

Bursa şehir endeksinde olduğu gibi İzmir şehir endeksi getiri serisinde tüm asimetrik koşullu değişen varyans modelleri için başarılı sonuçlar üretildiği görülmüştür (Tablo 10). Model seçim ölçütlerinin tümünde ve sapma oranı ölçütünde en iyi değerleri EGARCH modeli yakalamışken, MAE ve MAPE ölçütlerinde en düşük değeri TGARCH modeli üretmiştir. RMSE için ise APGARCH en iyi sonucu vermiştir. Model seçim ve tahmin performans ölçütlerinin tümü göz önüne alındığında nihai model EGARCH seçilmiş ve nihai modele ait hata terimlerinin koşullu dağglımlarını betimlemede en başarılı dağılım türünün Student-t olduğu sonucuna ulaşılmıştır.

Tablo 10. İzmir Şehir Endeksi Getiri Serisine Ait Ölçütler

\begin{tabular}{|c|c|c|c|c|c|c|}
\hline & $\begin{array}{c}\text { EGARCH } \\
\mathbf{N}\end{array}$ & $\begin{array}{c}\text { EGARCH } \\
\mathbf{T}\end{array}$ & $\begin{array}{c}\text { EGARCH } \\
\text { GED }\end{array}$ & $\begin{array}{c}\text { TGARCH } \\
\mathbf{N}\end{array}$ & $\begin{array}{c}\text { TGARCH } \\
\mathbf{T}\end{array}$ & $\begin{array}{c}\text { TGARCH } \\
\text { GED }\end{array}$ \\
\hline \multicolumn{7}{|c|}{ Model SeçimÖlçütleri } \\
\hline $\mathbf{L L}$ & 9281.721 & 9377.727 & 9362.801 & 9277.555 & 9374.507 & 9359.773 \\
\hline AIC & -7.334695 & -7.409828 & -7.398024 & -7.3314 & -7.407281 & -7.395629 \\
\hline SIC & -7.318542 & -7.391368 & -7.379564 & -7.315247 & -7.388822 & -7.377169 \\
\hline H-Q & -7.328834 & -7.40313 & -7.391326 & -7.325539 & -7.400584 & -7.388931 \\
\hline \multicolumn{7}{|c|}{ ÖngörüPerformansÖlçütleri } \\
\hline RMSE & 0.008383 & 0.008391 & 0.008392 & 0.008385 & 0.008410 & 0.008415 \\
\hline MAE & 0.006252 & 0.006251 & 0.006252 & 0.006250 & 0.006256 & 0.006255 \\
\hline MAPE & 114.2188 & 120.1791 & 120.2619 & 113.9497 & 123.6196 & 123.7890 \\
\hline SapmaOranı & 0.006252 & 0.010076 & 0.009954 & 0.006561 & 0.010617 & 0.010613 \\
\hline \multicolumn{7}{|l|}{ Model SeçimÖlçütleri } \\
\hline & $\begin{array}{c}\text { APGARCH } \\
\mathbf{N}\end{array}$ & $\begin{array}{c}\text { APGARCH } \\
\text { T }\end{array}$ & $\begin{array}{c}\text { APGARCH } \\
\text { GED }\end{array}$ & & & \\
\hline
\end{tabular}




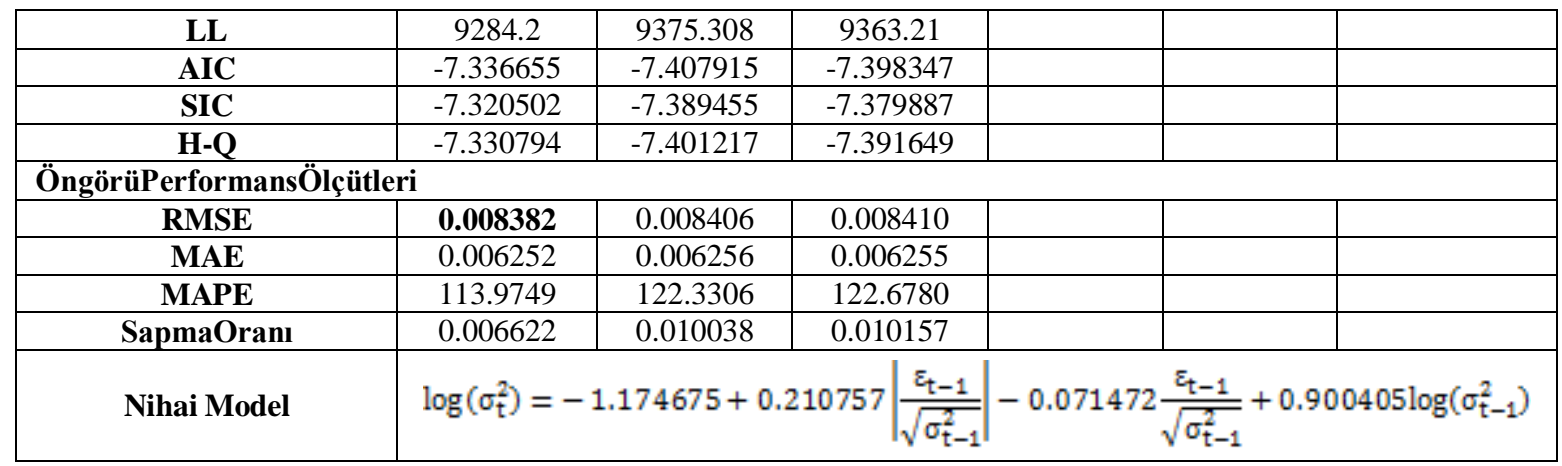

Kayseri şehir endeksi için Adım 1'de en iyi olma potansiyeli taşıyan modellerin model seçim ve öngörü ölçütlerine ait değerler Tablo 11 'de verilmiştir. Model seçim ölçütlerinin tümünde ve RMSE, MAPE ve sapma oranı öngörü ölçütleri için ortak olarak en iyi modelin APGARCH olduğu görülmektedir. Nihai olarak seçilen APGARCH modeli için Student-t dağılımını, hata terimlerine ait koşullu dağılımları betimlemede en başarılı dağılım türüdür.

Tablo 11. Kayseri Şehir Endeksi Getiri Serisine Ait Ölçütler

\begin{tabular}{|c|c|c|c|c|c|c|c|}
\hline & $\begin{array}{c}\text { EGARCH } \\
\mathbf{N} \\
\end{array}$ & $\begin{array}{c}\text { EGARCH } \\
\text { T } \\
\end{array}$ & $\begin{array}{c}\text { EGARCH } \\
\text { GED }\end{array}$ & $\begin{array}{c}\text { TGARCH } \\
\text { T } \\
\end{array}$ & $\begin{array}{c}\text { APGARCH } \\
\mathbf{N} \\
\end{array}$ & $\begin{array}{c}\text { APGARCH } \\
\text { T } \\
\end{array}$ & $\begin{array}{c}\text { APGARCH } \\
\text { GED }\end{array}$ \\
\hline \multicolumn{8}{|c|}{ Model SeçimÖlçütleri } \\
\hline $\mathbf{L L}$ & 8840.112 & 8962.185 & 8945.659 & 8961.855 & 8841.327 & 8962.28 & 8945.995 \\
\hline AIC & $\begin{array}{l}-6.982697 \\
\end{array}$ & -7.078407 & -7.065353 & -7.078146 & -6.983658 & -7.078482 & -7.065609 \\
\hline SIC & -6.96655 & -7.059953 & -7.046889 & -7.059693 & -6.967511 & -7.060028 & -7.047155 \\
\hline H-Q & -6.976838 & -7.071712 & -7.058648 & -7.071451 & -6.9778 & -7.071786 & -7.058913 \\
\hline \multicolumn{8}{|c|}{ ÖngörüPerformansölçütleri } \\
\hline RMSE & 0.011002 & 0.011027 & 0.011023 & 0.011024 & 0.011001 & 0.011027 & 0.011023 \\
\hline MAE & 0.008440 & 0.008446 & 0.008451 & 0.008442 & 0.008442 & 0.008448 & 0.008452 \\
\hline MAPE & 125.7465 & 136.4884 & 131.7170 & 137.1349 & 124.4764 & 135.8527 & 131.0299 \\
\hline SapmaOranı & 0.017338 & 0.020997 & 0.019379 & 0.021243 & 0.017101 & 0.020842 & 0.019206 \\
\hline Nihai Model & \multicolumn{7}{|c|}{$\sigma_{\mathrm{t}}^{\mathrm{d}}=0.001010+0.136633\left(\left|\varepsilon_{\mathrm{t}-1}\right|+0.373346 \varepsilon_{\mathrm{t}-1}\right)+0.762942 \sigma_{\mathrm{t}-1}^{1}$} \\
\hline
\end{tabular}

Kocaeli şehir endeksi getiri serilerine ait modelleme sonuçları Tablo 12'de verilmiştir. Model seçim ve öngörü ölçütlerinin tümüne göre en iyi modelin APGARCH olduğu görülmektedir. GED dağılımının ise nihai olarak seçilen APGARCH modeli hata terimlerine ait koşullu dağılımlarını betimlemede en başarılı dağılım türü olduğu bulunmuştur.

Tablo 12. Kocaeli Şehir Endeksi Getiri Serisine Ait Ölçütler

\begin{tabular}{|c|c|c|c|c|c|c|}
\hline & $\begin{array}{c}\text { EGARCH } \\
\text { N }\end{array}$ & $\begin{array}{c}\text { EGARCH } \\
\text { GED }\end{array}$ & $\begin{array}{c}\text { TGARCH } \\
\text { N }\end{array}$ & $\begin{array}{c}\text { TGARCH } \\
\text { GED }\end{array}$ & $\begin{array}{c}\text { APGARCH } \\
\mathbf{N}\end{array}$ & $\begin{array}{c}\text { APGARCH } \\
\text { GED }\end{array}$ \\
\hline Model SeçimÖlçütleri & 9014.894 & 9104.181 & 9005.99 & 9098.643 & 9017.885 & $\mathbf{9 1 0 5 . 5 0 1}$ \\
\hline LL & -7.120865 & -7.190657 & -7.113826 & -7.186279 & -7.123229 & $\mathbf{- 7 . 1 9 1 7 0}$ \\
\hline AIC & -7.104718 & -7.172203 & -7.097679 & -7.167825 & -7.107082 & $-\mathbf{7 . 1 7 3 2 4 6}$ \\
\hline SIC & -7.115006 & -7.183961 & -7.107967 & -7.179583 & -7.117371 & $\mathbf{- 7 . 1 8 5 0 0 5}$ \\
\hline H-Q & 0.007987 & 0.007948 & 0.007993 & 0.008001 & 0.007983 & $\mathbf{0 . 0 0 7 9 3 9}$ \\
\hline ÖngörüPerformansÖlçütleri & 0.006103 & 0.006063 & 0.006106 & 0.006105 & 0.006101 & $\mathbf{0 . 0 0 6 0 5 6}$ \\
\hline RMSE & 101.2098 & 101.1739 & 101.3732 & 103.2455 & 101.0333 & $\mathbf{1 0 0 . 5 3 6 9}$ \\
\hline MAE & 0.000529 & 0.001637 & 0.000548 & 0.001938 & $\mathbf{0 . 0 0 0 4 7 6}$ & 0.001554 \\
\hline MAPE & $\sigma_{\mathrm{t}}^{\mathrm{d}}=0.000658+0.111098\left(\left|\varepsilon_{\mathrm{t}-1}\right|+0.314473 \varepsilon_{\mathrm{t}-1}\right)+0.821212 \sigma_{\mathrm{t}-1}^{1}$ \\
\hline SapmaOranı
\end{tabular}


Son olarak Tekirdağ şehir endeksi için tahmin edilen 18 farklı modelin katsay anlamlılığı ve ARCH-LM test sonuçları göz önüne alındığında sadece EGARCH-Normal modelinin Adım 2 için seçildiği bulunmuştur. Diğer bir değişle nihai model, Adım 1'de seçilmiştir. Modele ait model seçim ve tahmin performans ölçütlerinin değerleri Tablo 13'de verilmişstir.

Tablo 13.Tekirdağ Endeksi Getiri Serisine Ait Ölçütler

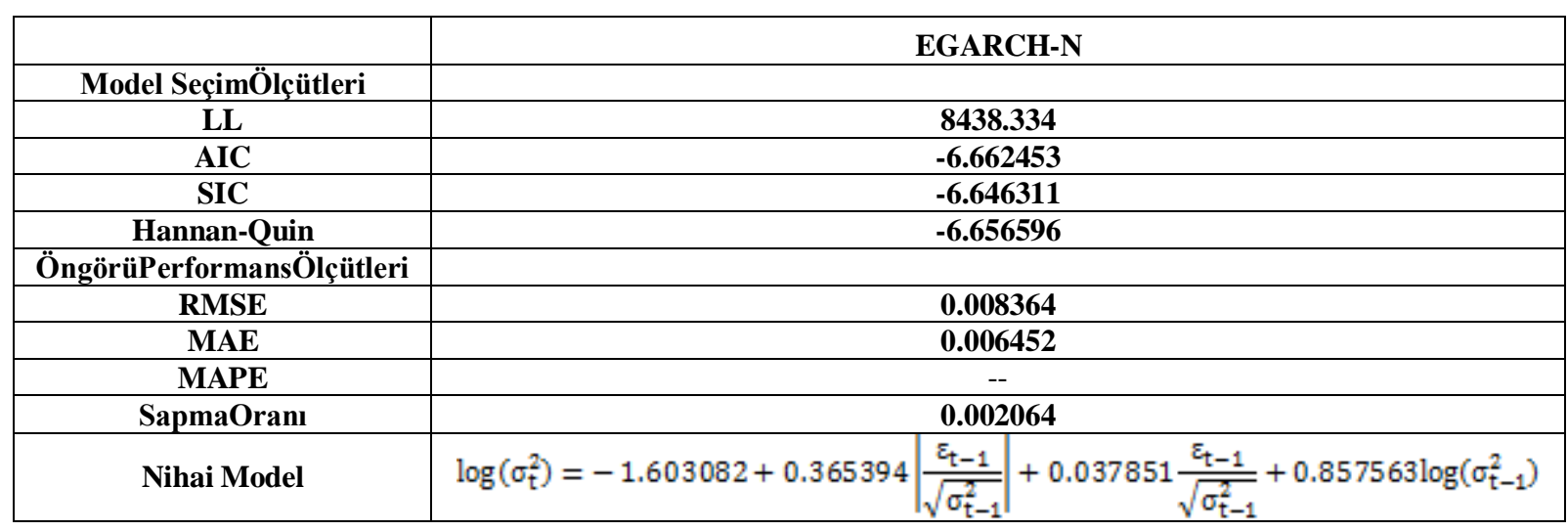

\section{SONUÇ VE DEĞERLENDİRE}

Şehir endeksleri BIST tarafından 2009 yılından itibaren hesaplanmaya başlanmış ve asıl hesaplanma amacının ilgili şehrin finansal performansı ölçmek olduğunu duyrulmuştur. Bir şehir endeksinin belirlenen kriterleri sağlayan en az 5 şirketin hisse senetlerinden oluşması, o endeksin bölgesel durumu yansitan bir portföy olma özelliği taşıdığı anlamına gelmektedir. Şehir endekslerinin bu özelliği, belirsizlik altında o bölgeye yatırım yapma kararı veren yatırımcıya ışık tutan bir rehber olma imkanı vermektedir. Bu sebeple bu endeksler ile ilgili son yıllarda yapılan çalışmalar şehir endeksi hesaplanan şehirlerin finansal performansın bir haritasını çizme özelliği taşımaktadır.

Bu çalışmada Adana, Ankara, Antalya, Bursa, İstanbul, İzmir, Kayseri, Kocaeli ve Tekirdağ şehir endekslerinin Şubat 2009 ve Mart 2019 yılları arasındaki getiri serileri incelenmiş ve tanımlayıcı istatistikler yardımıyla getiri serilerinin temel karakteristik yapıları araştırılmıştır. Günlük getiri serilerine ait volatilite, farklı simetrik ve asimetrik koşullu değişen varyans spesifikasyonları kullanılarak modellenmiştir. Finansal zaman serilerine ait hata terimlerinin dağılımlarında sıkça karşılaşılan leptokurtik yapı dikkate alınarak normal dağılım dışında Student-t ve GED dağılımı alternatifleri kullanılmıştır. Böylelikle her bir şehir endeksi için 18 farklı model tahmin edilmiş ve nihai modeller raporlanmıştır.

Nihai modellerin belirlenmesinde 2 adımdan oluşan bir karar verme süreci izlenmiştir. İlk olarak tüm veri seti için model tahminleri yapılmış, model katsayılarının anlamlılığ ve ARCH etkisinin olmaması gibi gereklilikler sonucunda en iyi olma potansiyeli taşıyan modellere ait ölçütler hesaplanmıştır. Sonrasında ise veri seti eğitim ve test olmak üzere ikiye ayrılmış, ilk adımda belirlenen modellerin öngörü performans ölçütleri hesaplanmıştır. Nihai modele, model seçim ve öngörü performans ölçütlerine dayanarak karar verilmiştir.

Dikkat çeken önemli sonuçlardan biri Antalya dışında tüm şehir endeksi serilerinde negatif ve pozitif şokların, endeks getiri serileri volatilitelerini asimetrik bir biçimde etkilediği 
görülmüştür. Antalya şehir endeksinde ise asimetrik modellemeler başarısız olmuş, GARCH spesifikasyonu nihai model olarak belirlenmiştir. Diğer dikkat çekici bir sonuç ise Tekirdağ şehir endeksi dışındaki tüm endekslerde negatif şoklar aynı büyüklükteki pozitif şoklara kıyasla daha fazla volatiliteye neden olmaktadır. Tekirdağ endeksinde ise bu durum tam tersidir yani, pozitif şoklar negatif şoklara kıyasla daha çok istikrar bozucudur.

EGARCH ile modellenen ve istatistiksel açıdan anlamlı bulunan asimetri katsayıları karşılaştırılacak olunursa, mutlak değerce en yüksek değer Kayseri şehir endeksine ait iken en düşük değer Adana şehir endeksine aittir. Buna göre Kayseri şehir endeksinin kötü haberlere karşı tepkisinin en hassas olduğu söylenebilir. Ayrıca $\beta$ katsayısının volatilite kalıcılığını ölçtüğü göz önüne alınırsa, göreceli olarak en düşük değeri Tekirdağ şehir endeksinin aldığ ve kötü haberlere karşı oynaklığının piyasada kısa sürdügü söylenebilir. En yüksek dayanıklılık değerinin Adana şehir endeksine ait olduğu ve bu endekse ait volatilitenin bir kriz ardından sönümlenmesinin diğerlerine oranla daha uzun zaman alacağı söylenebilinir.

Son olarak şehir endekslerine ait simetrik ve asimetrik GARCH tahminlerinde hata terimlerinin koşullu dağılımlarını betimlemede en başarılı dağılım türünün Student-t olduğu görülmektedir (Adana, Tekirdağ ve Kocaeli endeksleri dışında). Bu sonuç, finansal zaman serilerinin kalın kuyruklu yapısından ötürü standardize hataların dağılımını yakalamada Student-t dağılımının diğer diğer dağılım alternatiflerine kıyasla (özellikle normal dağılım) başarılı olduğunu gösteren Bollerslev (1987), Hsieh (1989), Baillie ve Bollerslev (1989), Bollerslev vd. (1992) ve Pagan (1996) 'ın çalışmalarını destekler niteliktedir.

\section{KAYNAKLAR}

Aksoy, Mine (2013), "İstanbul Menkul Kiymetler Borsası'nda Finansal Kriz Döneminde Yabanc1 Yatırımciların Hisse Senedi Tercihlerinin Analizi", IÜ Siyasal Bilgiler Fakültesi Dergisi, No. 48, ss. 135-150.

Alexander, Carol (2008), Practical Financial Econometrics, John Wiley\&Sons, Chichester, $\mathrm{UK}$.

Alizadeh, Amir H.- Nomikos, Nikos K. (2009), Shipping Derivates and Risk Management, Palgrave Macmillan, Basingstoke, UK.

Aşkın Öyküm Esra- Büyüklü Ali Hakan (2014), "Testing the Calendar Anomalies for BIST City Indexes with Symmetric and Asymmetric GARCH Models", İktisat İşletme ve Finans, Vol.29, pp.59-82.

Baillie, Richard T- Bollerslev, Tim (1989), "The Message in Daily Exchange Rates: A Conditional-Variance Tale", Journal of Business \& Economic Statistics, Vol. 7, No. 3, pp. 297-305.

Bayrakdaroğlu, Ali-Tepeli, Yusuf (2018), "BİST Şehir Endekslerinin Risk-Getiri Analizi Üzerine Bir İnceleme", Muhasebe ve Finansman Dergisi, Sayı. 80, ss.147-160. 
Bayramoğlu, Mehmet Fatih - Pekkaya, Mehmet (2010), “İMKB Tarafından Hesaplanan Endekslerde Yeni Gelişmeler ve İMKB Şehir Endeksleri”, Muhasebe ve Finansman Dergisi, Say1: 45, ss. 200-215.

BIST (2019), (http://borsaistanbul.com/endeksler/bist-pay-endeksleri/sehir-endeksleri, Erişim Tarihi: 08.02.2019).

Bollerslev, Tim (1986), “Generalized Autoregressive Conditional Heteroscedasticity” Journal of Econometrics, Vol. 31, No.3, pp. 307-327.

Bollerslev, Tim (1987), “A Conditional Heteroskedastic Time series Model for Speculative Prices and Rates of Return", The Review of Economics and Statistics, Vol. 69, No. 3, pp. 542-547.

Bollerslev, Tim-Chou, Ray Y.-Kroner, Kenneth F. (1992), “ARCH modeling in finance”, Journal of Econometrics, No. 52, pp. 5-59.

Çakır, Zahide (2016), "Şehir Endekslerinin Finansal Performanslarının Ölçülmesi ve Değerlendirilmesi, Yayımlanmamış Yüksek Lisans Tezi, Hitit Üniversitesi Sosyal Bilimler Enstitüsü, Çorum. Ankara Üniversitesi SBF Dergisi, Sayı. 65, No. 2, ss. 1-28.

Çiçek, Macide- Öztürk, Feride (2007), “Yabancı Hisse Senedi Yatırımcıları Türkiye'de Döviz Kuru Volatilitesini Şiddetlendiriyor mu?”, Ankara Üniversitesi Siyasal Bilgiler Fakültesi Dergisi, Sayı. 62, No. 4, ss. 83-107.

Devaslıgil Atmaca, Verda (2018), "BİST Şehir Endeksleri Oynaklığının DCC-GARCH Model ile Analizi", Yönetim Bilimleri Dergisi, Cilt: 16, Sayı: 31, ss. 287-308.

Dink, Zhuanxin-Granger, Clive W.J.-Engle, Robert F. (1993), “A Long Memory Property of Stock Market Returns and New Model”, Journal of Emprical Finance, Vol. 1, No.1, pp.83-106.

Duran, Serap-Şahin, Asuman (2006), “İMKB Hizmetler, Mali, Sınai ve Teknoloji Endeksleri Arasındaki İlişkinin Belirlenmesi”, Gaziosmanpaşa Üniversitesi Sosyal Bilimler Araştırma Dergisi, Sayı. 1, ss. 57-70.

Engle, Robert F. (1982), "Autoregressive Conditional Heteroscedasticity with Estimates of the Variance of United Kingdom Inflation", Econometrica, Vol. 50, No.4, pp. 9871007.

Engle, Robert F.-Lilien, David M.-Robins, Russel P. (1987), "Estimating Time-Varying Risk Premia in the Tern structure: the ARCH-M model", Econometrica, Vol. 55, No. 2, pp. 391-407.

Floros, Christos (2008), "Modelling Volatility Using GARCH Models: Evidence from Egypt and Israel", Middle Eastern Finance and Economics, No.2, pp.31-41. 
Glosten, Lawrence R.-Jagannathan, Ravi-Runkle, David E. (1993), “On the Relation Between the Expected Value and the Volatility of the Nominal Excess Return on Stocks" Journal of Finance, Vol. 48, No. 5, pp.1779-1801.

Gökçe, Atilla (2001), "İstanbul Menkul Kiymetler Borsası Getirilerindeki Volatilitenin ARCH teknikleri ile Ölçülmesi”, Gazi Üniversitesi İ.İ.B.F Dergisi ,Sayı. 3, No.1, ss.35-58.

Hsieh, David A. (1989), "Modeling Heteroscedasticity in Daily Foreign-Exchange Rates", Journal of Business \& Economic Statistics, Vol. 7, No. 3, pp. 307-317.

Kovacic, Zlatko (2007), "Forecasting Volatility: Evidence from the Macedonian Stock Exchange, MPRA Paper No. 5319.

Kula, Veysel-Baykut, Ender (2018), "BİST Şehir Endekslerinin Volatilite Yapıları ve Rejim Değişimlerinin Analizi", Muhasebe ve Finans İncelemeleri Dergisi, Sayı. 1, No.1, ss. 38-59.

Lee, Cheng F-Chen, Gong-meng- Rui, Oliver (2001), "Stock Returns and Volatility on China Stock Markets" Journal of Financial Research, Vol.24, No. 4, pp. 523-543.

Lopez, Jose A. (2001), "Evaluating the Predictive Accuracy of Variance Models", Journal of Forecasting, Vol. 20, pp. 87-109.

Miron, Dumitru-Tudor, Cristiana (2010), "Asymmetric Conditional Volatility Models: Emprical Estimation and Comparison of Forecasting Accuracy", Journal for Economic Forecasting No.13, pp. 74-92.

Nelson, Daniel (1991), "Conditional Heteroscedasticity in Asset Returns: A New Approach", Econometrica, Vol. 59, No. 2, pp. 347-370.

Nyberg, Henri (2010), "QR-GARCH-M Model for Risk-Return Tradeoff in U.S. Stock Returns and Business Cycles", University of Helsinki and HECER, Discussion Paper No.294, ISSN 1795-0562.

Özden, Ünal. H. (2008), "İMKB 100 Endeksi Getiri Volatilitesinin Analizi", İstanbul Ticaret Üniversitesi Sosyal Bilimler Dergisi, Say1. 7, No. 13, ss. 339-350.

Pagan, Adrian (1996), "The econometrics of financial markets", Journal of Empirical Finance, Vol.3, pp. 15-102.

Pagan, Adrian R.-Schwert, G. William (1990),"Alternative Models for Conditional Stock Market Volatility", Journal of Econometrics, Vol. 45, No.1-2,pp. 267-290.

Sentana, Enrique (1995), "Quadratic ARCH models", Review of Economics Studies, Vol. 62, No. 4, pp. 639-661.

Taylor, Stephen J. (1994), "Modelling stochastic volatility: A review and Comparative study", Mathematical Finance, Vol. 4, No. 2, pp. 183-204. 
Yaprakl1, Sevda-Bozma, Gürkan-Akdağ, Murat (2018), "BIST Şehir Endekslerinde Oynaklığın Ölçülmesi: Alternatif Ekonometrik Modellerin Karşılaştırmalı Olarak İncelenmesi", Finans Politik \& Ekonomik Yorumlar, No. 639, ss. 67-86.

Zakoian, Jean-Michel (1994), "Threshold Heteroskedastic Models", Journal of Economic Dynamics and Control, Vol. 18, No.5, pp. 931-955.

Zivot, Eric (2008), "Practical Issues in the Analysis of Univariate GARCH Models", http://www.faculty.washington.edu/ezivot/research/practicalgarchfinal.pdf, (20.03.2019). 